\title{
The Design and Application of Traditional Sports Events Information Processing Platform
}

\author{
Yang Zhang \\ Xi'an University of science and technology, Xi'an 710000, China \\ aawei@163.com
}

Keywords: Sports event, information processing platform, information system.

\begin{abstract}
With the gradual increase of the number of sports events and the participation in sports activities, the amount of information of sporting events will show exponential rate of growth, sporting events information provided by traditional library materials and newspaper media is unable to meet the current needs of researchers to study on sporting events. To build intelligent information platform of sporting events, and to implement intelligent sports events information collection, sports events information organization, and sports events information retrieval will become a prerequisite and basis for in-depth study on sporting events. And the rapid development of information technology, Internet, and artificial intelligence also provides the appropriate technical support for an intelligent information platform of sports events.
\end{abstract}

\section{Introduction}

As the world economy continues to develop rapidly, sport events have been promoted gradually to prosperity [1]. Especially the large-scale sport event like the Olympic Games is becoming a token reflecting the comprehensive power of a nation or a territory [2]. In recent 20 years China has played host to a myriad of large-scale sport events, such as the Asian Games, the World University Games and the Olympic Games. In wake of such prestigious events, China's sport management has accumulated much invaluable knowledge and experience. With such background this study tries to explore systematically sport event organization and operation directed by knowledge management theory, in order to enrich and perfect the theory of event management making the future sporting events more reasonable, scientific and regulated.

As an important part of sports event information display system, the management software is in charge of collecting, processing and publishing information instantly. There are some jobs in the development of the management software for different sports events.

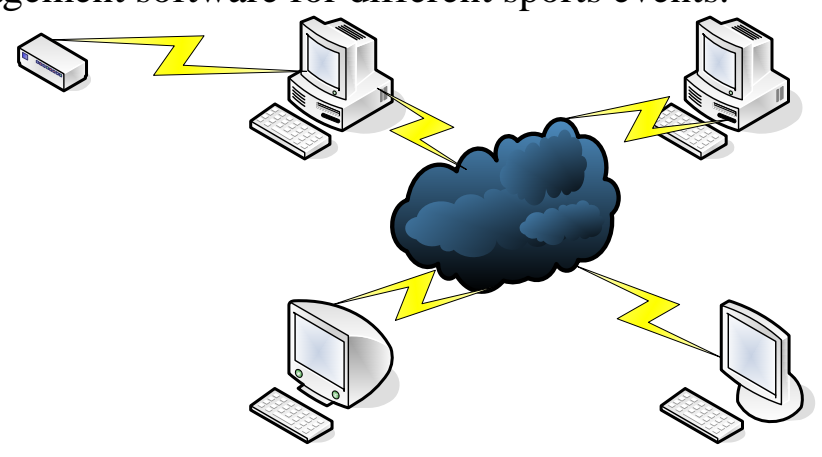

Fig. 1 The network topological

As the development of computer and information technology, since the 1980s, the input of information technology always counts $50 \%$ of the total expenditure. Although technology could improve the production efficiency, it should be firstly accepted by the organizers. The study of the acceptance of users to the technology is one of the most mature fields in the study of modern information system. There are many theatrical models in this field, among which the most representational is Theory Acceptance Model (TAM), proposed by Davis in 1989. [3] It was developed based on Theory of Reasoned Action (TRA) by Fishbein and Ajzen in 1975. Besides, in 
1992, after studying the related theories [4], Delone and McLean put forward the six elements for the success of information system to explain ISSM [5]. The six elements are namely system quality, information quality, system application, user's satisfaction, individual influence and organization influence. The network topological is shown in Fig. 1.

This paper analyzes the rules and requirements of various types of sports, and constructs the universal structure of management software which based on universal modules. The universal structure consists of timing subsystem, recording subsystem and network communication module. The timing subsystem uses double buffering to avoid flickering display; the network communication module uses dual-port technology to improve the efficiency of information transmission; the recording subsystem uses XML technology universal structure to store and share information. Development on the basketball management software can collect and publish the information instantly. The national games data processing in 2013 is shown in Fig. 2.

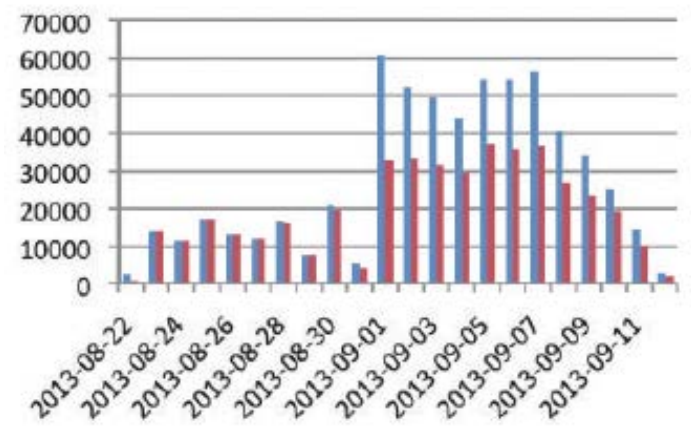

Fig. 2 The national games data processing in 2013

\section{Software analysis}

Sports competition is regarded as one of the important parts in sports industry. The technical statistics and the video analysis of sport games play very important roles in the technical-tactical research and adversary analysis. The means of technical statistics can be divided into traditional pen and paper method and computer tool method. The correlation between the software design and the level of applying computer software in the tech stats is very strong. Currently there's still no successive application software in the technical stats in beach volleyball in our country and abroad. XML files and DOM structure are as shown in Fig. 3, while system main interface is shown in Fig. 4.

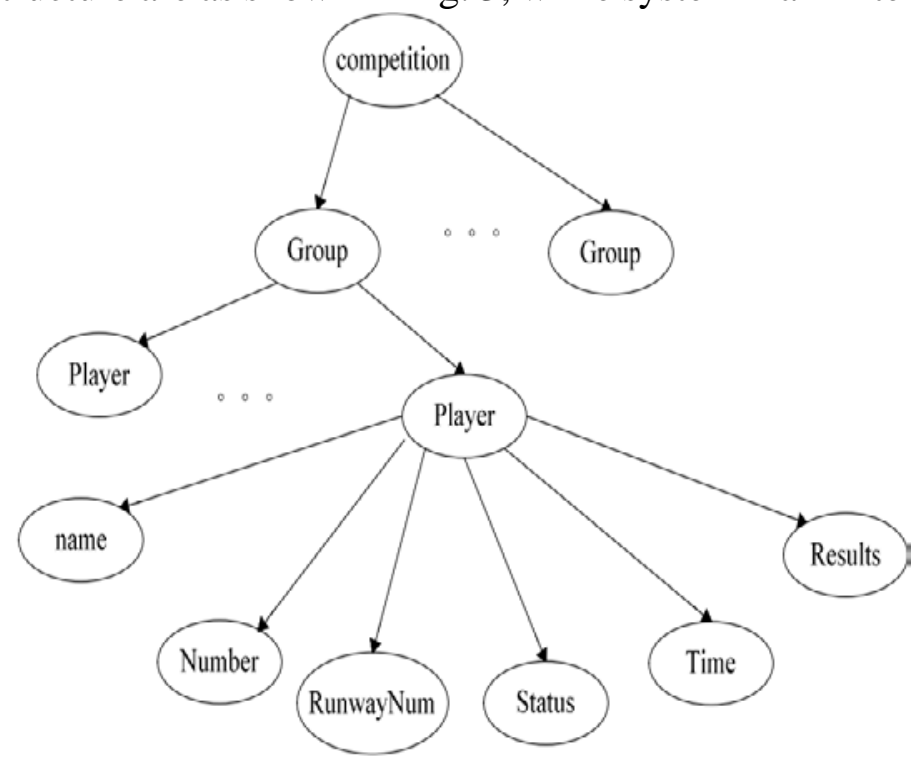

Fig. 3 XML files and DOM structure 


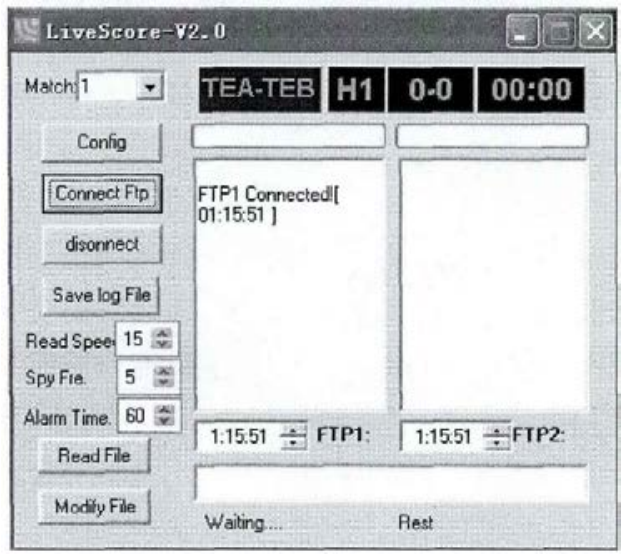

Fig. 4 System main interface

\section{Database Design}

According to the system function requirements, teaching system is more and more important. The Internet long-distance teaching system based on web technology is a new pattern of teaching which utilizes Internet as carrier of information to form an independent and distributed teaching environment. As the popularity of the Internet, the network teaching system based on web technology will be the main pattern of the future education. Main factor analysis list follows as Table 1.

\section{Table 1 Factor analysis}

\begin{tabular}{ccc}
\hline & System quality & Information quality \\
\hline SYSQ-1 & 0.704 & 0.227 \\
SYSQ-2 & 0.751 & 0.274 \\
SYQL-3 & 0.774 & 0.262 \\
SYQL-4 & 0.780 & 0.112 \\
INFOQ-1 & 0.423 & 0.706 \\
INFOQ-2 & 0.324 & 0.728 \\
INFOQ-3 & 0.174 & 0.746 \\
INFOQ-4 & 0.176 & 0.724 \\
SERVSQ-1 & $5.495 E-2$ & 0.201 \\
SERVSQ-2 & $8.681 E-2$ & 0.432 \\
SERVSQ-3 & 0.105 & 0.003 \\
SERVSQ-4 & 0.213 & 0.120 \\
SERVSQ-5 & 0.013 & 0.267 \\
TOTAL & $45.197 \%$ & $54.803 \%$ \\
\hline
\end{tabular}

\section{The main function modules of the system}

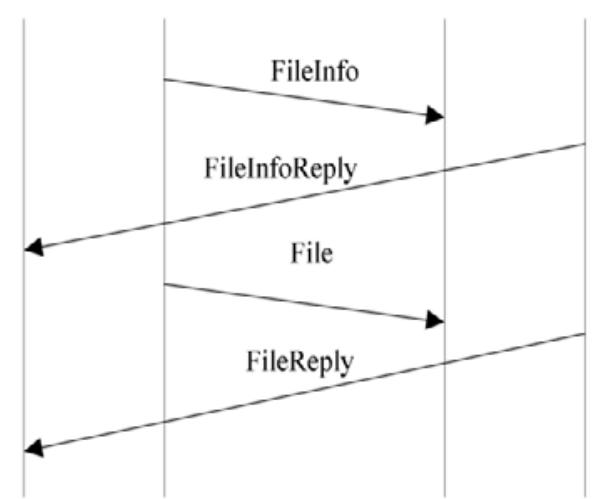

Fig. 5 Input and output

In order to make full use of the education resources and raise the mutuality and the initiative of teaching, in this thesis, a net teaching system based on web is exploited and implemented by JSP technology. This thesis adopts B/S three-tiered structure mode, uses the SQL Server 2000 as the 
database platform and provides the functions of registration, login, On-line Learning, teachers and students exchange, system management etc. The results of testing show that the system runs reliably and efficiently and is a comprehensive, stable and flexible network teaching system that improves the interactive and initiative of instructing on web greatly, which will fundamentally mobilize the positivist and initiative of the students and stimulate the students' motivation, and create a favorable atmosphere.. As shown in Fig. 5.

\section{Part of the key codes}

$<$ form name="formal" method="post"action= "/JspWebApp/ loginservlet" $>$

$<$ p>\&dsde;\&nbsp; names :cipher<input name="name" types="text" id="name" size $=" 11$ ">

\&nbsp;\&desdbsp; users type:<selecting name="type">

$<$ option to values="administration" $></$ options $>$

$<$ option to values="teacher" $><$ option $>$

$<$ option to values="student" $></$ option $>$

$</$ select $>$

package and espespsapp;

importing for javax.servleting .http.*

import to pritsrime javax.servlet.*;

import with java.util.*;

import for javascrept.io.*;

importing to java.naming.*;

\section{Conclusions}

Software system design of sports events information platform not only needs to follow the methodology of software engineering, but also needs to consider scalability, adaptability and flexibility and so on of the system. This paper aims at a series of issues currently existing in research area on sports events, i.e. single research information, fragmented, non-system and so on, after a detailed system requirements analysis, and based on the adaptability and scalability requirements of sports events information system platform, research on framework of sports events information system platform. Based on Multi-Agent technology of sports events information system platform, a framework should be built and verified by related design of software engineering, rapid prototyping, system comparison. The results show that, information system platform framework based on Multi-Agent technology has certain advantages in practicality, scalability and adaptability.

\section{References}

[1] B. Bolte. A Virtual Reality Handball Goalkeeper Analysis System. Virtual Reality Conference of EuroVR-EGVE-VEC, 2010.

[2] Oliva, P. F. Developing the curriculum. 3rd ed. Boston\&Toronto:Little, Brown and Company, 2008: 257, 259-261.

[3] Ken Green. Key themes in youth sport. London and New York:Routledge, 2010: 41.

[4] Information on http://www.teamhb.org

[5] Information on http://www.inf.info 